\title{
Biliary Ascariasis
}

\author{
Sardar Rezaul Islam ${ }^{1 *}$, Majedul Islam ${ }^{1}$, Shah Poran ${ }^{1}$, Mushfiqur Rahim ${ }^{1}$ and Shafiqur Rahman ${ }^{2}$ \\ ${ }^{1}$ Department of Surgery, Jahurul Islam Medical College \& hospital, Bangladesh \\ ${ }^{2}$ Department of Radiology and Imaging, Jahurul Islam Medical College \& hospital, Bangladesh
}

Submission: March 14, 2019; Published: April 03, 2019

${ }^{*}$ Corresponding author: Sardar Rezaul Islam, Department of Surgery, Jahurul Islam Medical College \& hospital, Bangladesh

\begin{abstract}
One quarter of world's population is known to be affected by ascariasis. It is endemic in various parts of the subcontinent. Gangetic plain of Bangladesh, West Bengal, Kashmere valley are examples. Biliary ascaiasis is one of the manifestations of ascariasis. We searched literature published from both endemic and non-endemic area and aimed to study different types of clinical presentation, diagnostic tool, complications and their frequency and various treatment option for the management of biliary ascariasis. Biliary colic is the commonest symptom. Acute cholecystitis, obstructive jaundice, cholangitis, pancreatitis, hepatolithiasis, liver abscess are other mode of presentation. Ultrasonography is an excellent non -invasive investigation for diagnosis and follow up of this condition. Majority of cases are treated conservatively. ERCP (Endoscopic Retrograde Cholangio Pancreatography) based extraction of Ascaris lubricoids is possible in most of the situation where expert endoscopy services are available. Open common bile duct exploration and removal of worm is necessary in absence of endoscopy. Improvement of personal hygiene, improvement of sanitation and regular anti-helminthic administration can reduce this dreadful consequence of infestation by worms.
\end{abstract}

Keywords: Biliary ascariasis; Endoscopic retrograde cholangio pancreatography; Common bile duct exploration

\section{Introduction}

Ascaris lumbricoides, a nematode, is the causative agent of ascariasis. It is the most common helminthic infestation in the world. Ascaris infestations are prevalent mainly in developing countries. People from lower socioeconomic group living in poor hygienic condition in rural areas are victim of this condition.

Table 1: Presentation of biliary ascariasis in various literature (Source $\left.{ }^{2}\right)$

\begin{tabular}{|c|c|}
\hline Presentation /Complication & Percentage \\
\hline Abdominal or biliary colic & $97 \%$ \\
\hline Acute cholangitis & $15.50 \%$ \\
\hline Obstructive jaundice & $9 \%$ \\
\hline Acute pancreatitis & $6.50 \%$ \\
\hline Choledocholithiasis & $6.50 \%$ \\
\hline Acute cholecystitis & $6.50 \%$ \\
\hline Liver abscess & $2.50 \%$ \\
\hline
\end{tabular}

Adult worm normally lives in small intestine. They love to wander and tend to explore ducts and cavities. The adult worm often enters bile and pancreatic duct and cause obstruction to the flow of bile or pancreatic juice. After gall stone, biliary ascariasis is the second most common cause of acute biliary symptom worldwide [1]. Female and children are mostly affected. Acute upper abdominal colic is the commonest symptom. In endemic ar eas biliary ascariasis is a frequent diagnosis and should be kept in mind for acute upper abdominal pain. Mainstay of diagnosis is ul trasonography. Most of the patient can be managed conservatively. Failure of conservative treatment will require worm extraction by ERCP or common bile duct exploration (Table 1-4).

Table 2: Presentation of biliary ascariasis in various literature (Source ${ }^{1}$ )

\begin{tabular}{|c|c|}
\hline Abdominal or Biliary Colic & $\mathbf{9 5 \%}$ \\
\hline H/O cholecystectomy & $80 \%$ \\
\hline H/O Sphincterotomy & $77 \%$ \\
\hline Acute cholangitis & $17 \%$ \\
\hline Obstructive jaundice & $28 \%$ \\
\hline Acute Pancreatitis & $2.50 \%$ \\
\hline Hepatic abscess & $2.50 \%$ \\
\hline
\end{tabular}

Table 3: Presentation of biliary ascariasis in various literature (Source $\left.{ }^{3}\right)$

\begin{tabular}{|c|c|}
\hline Presentation /Complication & Percentage \\
\hline Abdominal or biliary colic & $80 \%$ \\
\hline Cholecystitis & $30 \%$ \\
\hline Obstructive jaundice & $25 \%$ \\
\hline Acute cholangitis & $5 \%$ \\
\hline Acute Pancreatitis & $5 \%$ \\
\hline Hepatic abscess & $5 \%$ \\
\hline
\end{tabular}

Table 4: Presentation of biliary ascariasis in various literature (Source $\left.{ }^{10}\right)$

\begin{tabular}{|c|c|}
\hline Presentation /Complication & Percentage \\
\hline Abdominal or biliary colic & $98 \%$ \\
\hline
\end{tabular}




\section{Advanced Research in Gastroenterology \& Hepatology}

\begin{tabular}{|c|c|}
\hline H/O cholecystectomy & $80 \%$ \\
\hline H/O Sphincterotomy & $77 \%$ \\
\hline H/O Worm emesis & $25 \%$ \\
\hline Obstructive jaundice & $1.30 \%$ \\
\hline Cholangitis & $16 \%$ \\
\hline Pancreatitis & $4.30 \%$ \\
\hline
\end{tabular}

Diagnosis
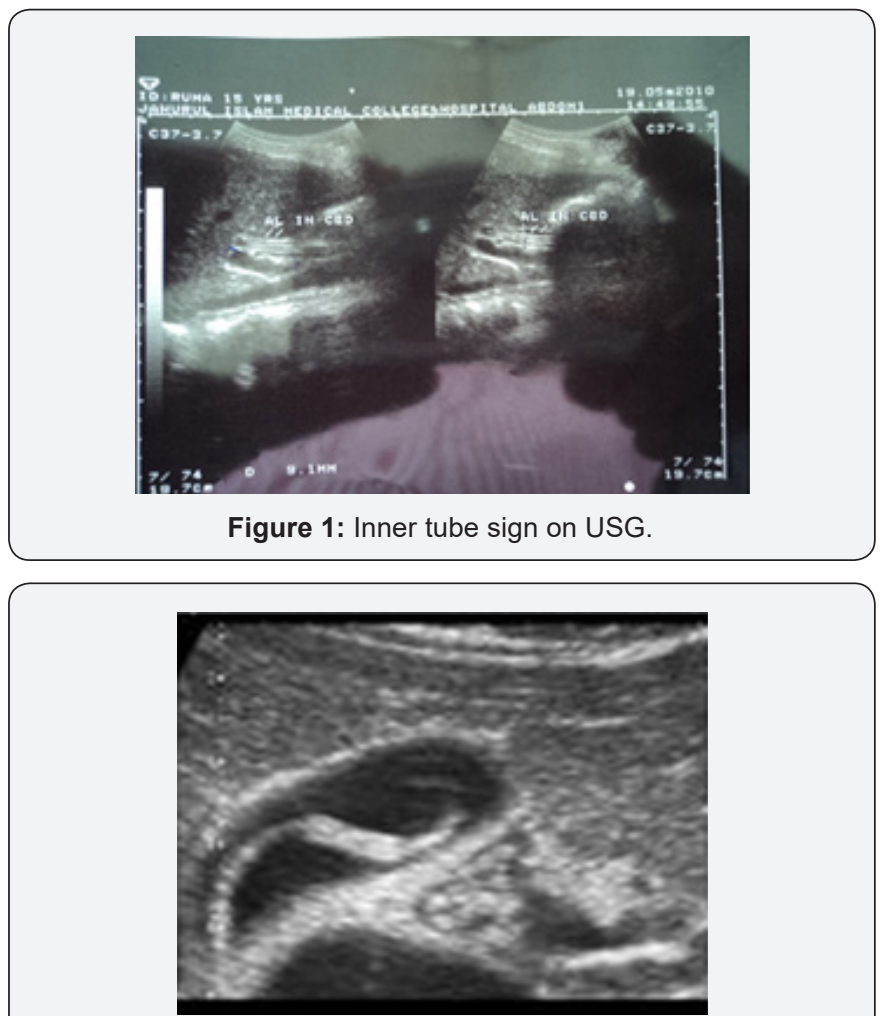

Figure 2: Stripe sign.

All patients with suspected biliary ascariasis are assessed with $\mathrm{CBC}$, liver function tests, serum amylase, X-ray chest and abdomen and ultrasonography of the hepatobiliary system. Ultrasonography should be repeated to assess the progress of the worm, whether it has passed out of the biliary tract or migrated upwards. The mainstay of diagnosis is ultrasonography [2]. It has a very high accuracy for diagnosis and follow up of worm in the biliary tract. Various appearance of the worm have been described on ultrasonography. They are as follows:

a) Inner tube sign: The worm may be seen as thick echogenic stripe with a central anechoic tube in the Gall bladder or common bile duct (Figure 1).

b) Stripe sign: Thin non shadowing stripe without and inner tube within the biliary tract (Figure 2).

c) Spaghetti sign: Multiple long linear overlapping echogenic structure due to coiling of a single worm or multiple worm.

d) Mobile structure: The sonography may demonstrate mobility of the worm in the gall bladder or the biliary channel and unequivocally establishing the diagnosis $[2,3]$.

e) Amorphous appearance: Degraded worm may appear as amorphous, echogenic filling defect making the diagnosis difficult.

f) Dilated intra and extrahepatic ducts will be present with any of the above-mentioned feature.

\section{Treatment}

All patients are initially managed conservatively with Intravenous fluid, antibiotic, analgesic and antispasmodic drug. Patients are followed by repeated ultrasound to see the progress of the worm. Majority of patients responds to this conservative therapy.

Failed conservative treatment should have worm extraction by ERCP if available or by open choledochotomy. In case of associated inflamed gall bladder cholecystectomy should be done. Liver abscess or perforation of hollow viscus will require surgical exploration.

All patients should be de-wormed with $400 \mathrm{mg}$ Albendazol and repeated in every 6 months interval (Figure $3 \& 4$ ).
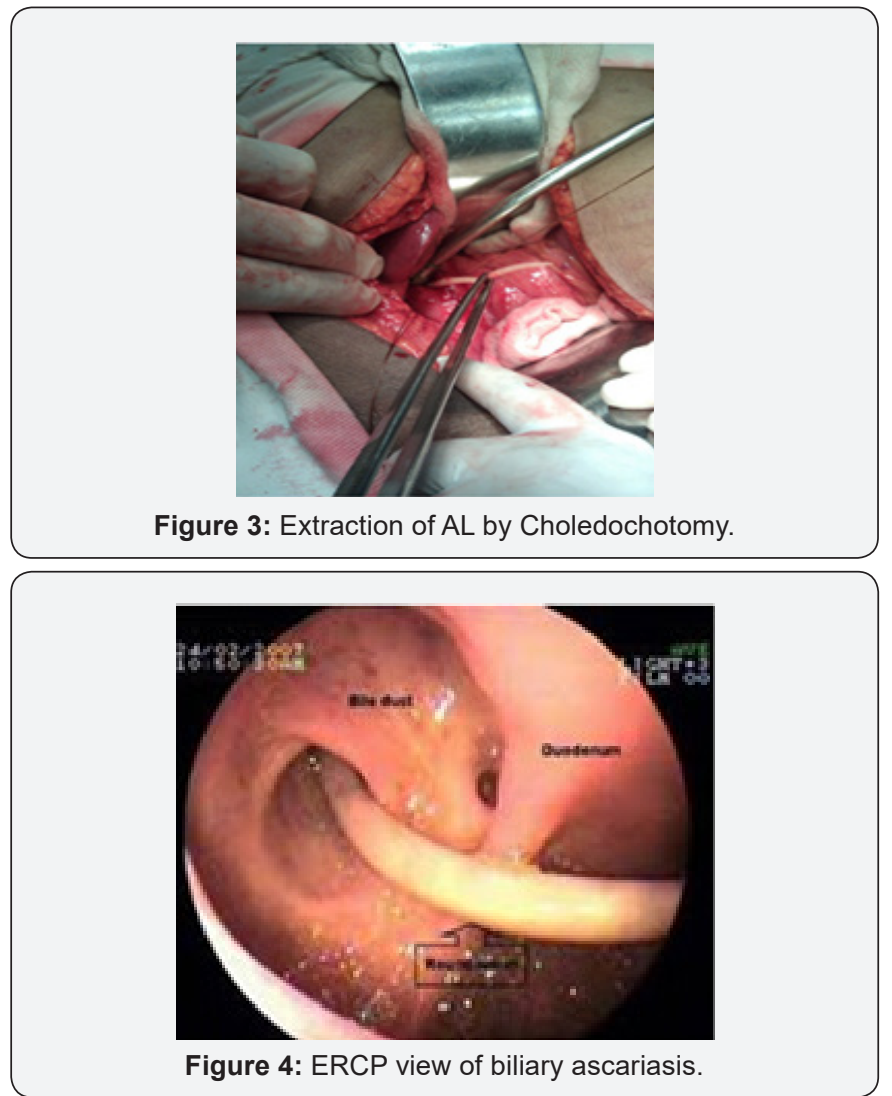

\section{Discussion}

Biliary ascariasis is commonly reported from Far-east, Indian subcontinent, Middle East, Latin America and Africa. In human the usual habitat is small intestine. When the worm load is high the worm tends to migrate out of the usual site of their habitat and tends to enter ducts and cavities [1].

Symptoms of biliary colic occurs when the worm migrates across the papilla in the duodenum. The worm may remain in the bile duct, may reach the gall bladder or even reach the hepatic parenchyma. As soon as it enters the bile duct colicky pain starts. If it 
stays in the biliary tract further complication may occur. Common complications noted in different series are cholangitis, stricture, calculi, cholecystitis, perforation of the CBD or gall bladder [4], pancreatitis and liver abscess.

Women are 4 to 6 time more affected than men. The reason behind the preponderance of female population is not exactly known. Young and middle-aged female possess high level of progesterone hormone. One of the actions of progesterone is relaxation of smooth muscle. Relaxation of smooth muscle of sphincter of Oddi allows worms gain easy entrance into the common bile duct [5]. recurrent duct invasion has been observed in the endemic region. Re-invasion rate has been found to be about $15 \%$. Previous surgery of the biliary tract predisposes to biliary ascariasis. Cases are reported after sphincterotomy and Roux-en-Y hepatico-jejunostomy [6]. Prior cholecystectomy also predisposes to bile duct invasion by ascariasis. After cholecystectomy common bile duct and other biliary ducts get dilated. Rise in the level of cholecystokinin leads to relaxation of sphincter of Oddi. All these factors help entry of ascaris into the biliary tree [7].

For diagnosis of biliary ascariasis ultrasound was described to have very high accuracy in most of the series. It is an excellent tool for monitoring progress of the worm in the biliary tree. Its accuracy was found to be around $100 \%$ in various series. ERCP has both diagnostic and therapeutic value.

Most of the series described high success of conservative treatment. Its reported efficacy ranges between 70 to $90 \%[8,9]$. All patients should be monitored by serial ultrasonography. Mostly patients improve on the conservative treatment within 4-5 days. Conservative treatment should not be continued for more than 10 days. Otherwise retained and degraded worms may lead to dreadful complication like CBD perforation, gall bladder perforation, cholangitis, liver abscess, which are difficult to manage [4]. If facility for endoscopic extraction is available therapeutic intervention should be done earlier. Mobbing Khan \& Annand BS demonstrated high success rate with wide papillotomy and endoscopic extraction in their series. They were successful in extraction of worm from the biliary tract around 95\% of cases. They did not experience any major complication during or following the procedure $[10,11]$. Failure or unavailability of ERCP will require surgical exploration of CBD and removal of the worm. Most of the surgeon like to put T-tube drainage after CBD exploration. In my experi-

\section{This work is licensed under Creative}

Commons Attribution 4.0 License

DOI: 10.19080/ARGH.2019.12.555847 ence a much-dilated CBD can be closed primarily without T-tube drain. Associated complication like liver abscess or cholecystitis can be dealt with at the time of surgical exploration.

\section{Conclusion}

In endemic areas upper abdominal pain in female and younger patient diagnosis of biliary ascariasis should be considered and ultrasound should be done for evaluation and follow up. Though majority of patient improves on conservative management early intervention by ERCP if facility is available. Conservative treatment must be abandoned in favor of surgery if worm does not come out of the biliary tract within 10 day's time. All patients must have regular de-worming as re-invasion rate is also very high in endemic area.

\section{References}

1. Madhumita Mukhopadhaya (2009) Biliary ascariasis in the Indian Sub-continent-a study of 42 cases. Saudi J Gastroenterol 15(2): 12-124.

2. Mani S, Merchant H, Sachdev R, Ranavare R, Chunha N (1997) Sonographic evaluation of biliary ascariasis. Australas Radiol 41(12): 204204.

3. Ashiana Garg, Vijay Hanchate, Soni Chawala, Preeti Sing (2006) Biliary ascarasis. Applied Radiology 31(12).

4. Wani MY, Ahmed Bashir, Wani AN, Pandita S (2005) J Indian Association of Paediatric surgeon 10: 86-88.

5. SP Misra, Manish Dwivedi (2000) Clinical feature and management of biliary ascariasis in non-endemic area. Postgraduate Medical J 76(891): 29-32.

6. Braga LH, Tatsuo ES, Guimaryes JT, Miranda ME, Paxio RM, et al. (2000) Biliary ascariasis after Roux Y -hepatico jejunostomy. J Pediatr Surg 35(9): 1394-1395.

7. Omer Javed Shah, Manzoor Ahmed Dar, Nazir Ahmed Wani, Irfan Rabbani, Showkat A Zragar (2004) Biliary ascaria sis as cause of Post cholecystectomy in an endemic area. Dig Surg 21(2): 108-113.

8. Chowdhury SY, Kaiser MS (2006) Varied presentation of biliary ascariasis and its consequences. Mymensingh Med J 15(2): 150-152.

9. K Shivkumar, Sam Varkey, Mathan P Georges, S Rajudran, R Hema (2007) Biliary ascariasis. Journal of Indian Association of Pediatric surgeon 12(2): 85-88.

10. Alam S, Mustafa G, Ahmed N, Khan M (2007) Presentation and Endoscopic Management of Biliary Ascariasis. South Asian J Tropical Medicine and Public Health 38(4): 631-635.

11. Sadouk F, Haffar S, Zadda MM, Graham DY, Ahmed BS (1997) Pancreatic and Biliary ascariasis. Experience of 300 cases. Am J of Gastroenterol 92(5): 2264-2267.

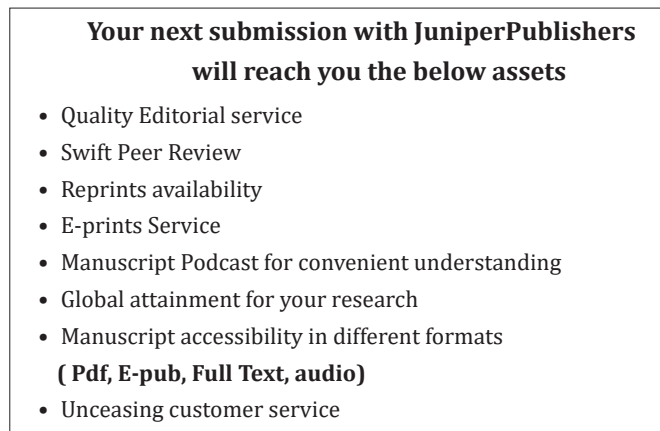

Track the below URL for one-step submission https://juniperpublishers.com/online-submission.php 